\title{
Online national program for family physicians' update and academic development
}

\author{
Miguel Ángel Rodríguez-Weber \\ e-Pronadameg, Academia Nacional de Medicina, Ciudad de México, Mexico
}

Since its foundation on April 30, 1864, one of the purposes of the National Academy of Medicine of Mexico has been to promote and facilitate all physicians' update; to accomplish this, it has used different strategies over time.

In 1993, doctor Juan Ramón de la Fuente, director of the National Autonomous University of Mexico (UNAM Universidad Nacional Autónoma de México) Faculty of Medicine and doctor Víctor Espinosa de los Reyes, then chairman of the National Academy of Medicine of Mexico, decided that the training course for graduates from the Faculty of Medicine itself who aspired to take the national exam for medical residency applicants should be moved to the National Academy of Medicine of Mexico.

In 1994, the National Program for General Physicians' Update and Academic Development (Pronadameg - Programa Nacional de Actualización y Desarrollo Académico) was created, in charge of Dr. Luis Martín Abreu as director and Dr. Alejandro Treviño Becerra as deputy director. From 1998 to 2010, the program was directed by Dr. Manuel de la Llata Romero and Dr. Juan Urrusti Sanz as director and deputy director, respectively. In July 2010, Dr. Juan López Bárcena was appointed as Pronademeg director, who was in that charge until November 2014.

Initially, the main purposes of the program were:

- To keep primary care physicians updated during their professional practice and support them in their development.

- To update and deepen general practitioners knowledge with programs conformed in a strategy that addresses the country's primary care medicine current and future needs.

- To disseminate the knowledge of medicine in order to better address health problems of the population.

- To guide primary care physician's performance criteria.
- To contribute to raise academic quality criteria in the practice of primary care medicine.

As of 1994 and until 2016, the National Academy of Medicine of Mexico, through Pronadameg, fostered the development of self-direction in continuing medical education and promoted a program with different updating options:

1. In-person diploma course. Imparted for more than 22 uninterrupted years until 2015, it was designed in such a way that interested parties could be able comply with the updating process in a module-regulated system. During that period, 88 sites were opened with support from 33 universities in 29 states of the country, which shared the same curricular core. With this modality, Pronadameg has had 12125 physicians enrolled, out of which 8019 have obtained the diploma?

2. Distant diploma. It is essentially based on the physician's updating by means of a series of publications addressing the subjects in instalments corresponding to different fields of medicine (last version, two volumes of PAC-General Medicine, fifth edition, 2014.

3. Prodanameg online (e-Pronadameg). This distant Program modality was initiated in 2006 by using CD's; it was composed of the subjects of the Update Diploma Course developed at the National Academy of Medicine, duly recorded and edited, which had study guides and clinical cases added.

In November 2014, doctors Enrique Ruelas Barajas and Enrique Graue Wichers, chairman and vice chairman of the National Academy of Medicine, appointed Dr. Miguel Ángel Rodríguez Weber as Pronadameg director, with recommendations to update, modernize, standardize and spread the program nation-wide.
Date of reception: 22-01-2016

Date of acceptance: 30-04-2016

DOI://dx.doi.org/10.24875/GMM.M18000141
Gac Med Mex. 2018;154:219-220

Contents available at PubMed www.gacetamedicademexico.com 


\section{e-Pronadameg development}

Following doctors Ruelas and Graue instructions, simultaneously with the traditional in-person program, in 2015 was the e-Pronadameg project initiated, which was able to be launched on March 2016 and that has the support of doctor Armando Mansilla Olivares, current chairman of the Academy.

The National Academy of Medicine, with the purpose to adapt to current needs and to modernize and standardize Pronademeg, decided to focus on the development of contents in priority aspects for primary care physicians and for Mexico's Health Sector by transforming the traditional in-person course into an online course the contents of which are available 24 hours a day, 365 days a year.

Current program contents have been transformed and designed to offer first-contact doctor (primary care physician and trainees on social service) a versatile program for continued education and permanent consultation that enables updating of his/her knowledge through a cutting-edge platform and that facilitates improving the quality of care provided to his/her patients, as well as acquiring more security and satisfaction on his/her knowledge grounding. On the other hand, physicians who wish to prepare to take the exam for medical residency aspirants find in e-Pronademeg a valuable tool for the achievement of their goals.

\section{e-Pronademeg platform}

Initially, the duration of the diploma course was programmed for 24 months, with inclusion of three more subjects every month after its initiation, to conclude with a total of 60 subjects. Currently, the totality of the program is available online and has:

- An individual student assessment and report automated system by State of the country, among others.

- Evaluations proposed by widely recognized teachers in the field of teaching and experts on each subject.

- 60 online conferences with health priority subjects, divided in 5 modules.

- PAC-5 (Continuous Update Program for the Primary Care Physician) e-book.

- Clinical-therapeutic Information Newsletter (National Academy of Medicine of Mexico bimonthly publication), updated with the complete publications of the preceding 3 years.

- Clinical practice guidelines.

- Clinical cases specifically prepared for the course.
The evaluation system enables the student to perform individual assessments per module, to obtain individual reports and users' statistics, the issue of certificates by the National Academy of Medicine of Mexico at the end of each module and to obtain the final diploma issued by the UNAM Faculty of Medicine for students enrolled in the diplomate course at the university. The passing grade is 8.0 for each subject.

\section{Endorsement}

The course adds up 200 points ( 30 for each module and an additional 50 for those who successfully conclude the 5 modules), which are acknowledged for the primary care physician recertification granted by the National General Medicine Regulatory Committee (Conamege - Comité Normativo Nacional de Medicina General A. C.) and with endorsement of the National Academy of Medicine of México; in addition, students who successfully conclude the 5 modules and who have enrolled in the diploma course at the Faculty of Medicine will obtain the corresponding diploma issued by UNAM.

\section{Trainee physicians on social service}

With the purpose to support medical trainees on social service, the National Academy of Medicine of Mexico has granted scholarships for the program to physicians graduated from the UNAM Faculty of Medicine; to date, 457 primary care physicians and medical trainees on social service have enrolled, and some of them are successfully concluding the course.

Among the plans for e-Pronademeg, its progressive broadening and permanent update are contemplated, thus complying in the best manner with the goals set forth by those who had the initiative in 1994 and who carried out its renewal in 2015.

At the initiative of the National Academy of Medicine of Mexico, the efforts of public and private institutions that have collaborated to the embodiment of the course have been brought together, including, in addition to the National Academy of Medicine, the UNAM Faculty of Medicine, Conacyt, the Gonzalo Río Arronte Foundation, the Nestle Mexico Company and the Intersistemas publishing house, which represents an example of ethical participation of institutions of different nature in an effort to facilitate primary care physicians update and academic development and to directly support trainee physicians on social service. 